\title{
Synthesis of aromatic glycoconjugates. Building blocks for the construction of combinatorial glycopeptide libraries
}

\author{
Markus Nörrlinger and Thomas Ziegler ${ }^{*}$
}

\author{
Full Research Paper \\ Address: \\ Institute of Organic Chemistry, University of Tuebingen, Auf der \\ Morgenstelle 18, 72076 Tuebingen, Germany \\ Email: \\ Thomas Ziegler* - thomas.ziegler@uni-tuebingen.de \\ * Corresponding author \\ Keywords: \\ amino acids; aniline; carbohydrates; glycoconjugates; glycopeptides
}

Beilstein J. Org. Chem. 2014, 10, 2453-2460.

doi:10.3762/bjoc. 10.256

Received: 13 August 2014

Accepted: 10 October 2014

Published: 22 October 2014

Associate Editor: S. Flitsch

(C) 2014 Nörrlinger and Ziegler; licensee Beilstein-Institut. License and terms: see end of document.

\begin{abstract}
New aromatic glycoconjugate building blocks based on the trifunctional 3-aminomethyl-5-aminobenzoic acid backbone and sugars linked to the backbone by a malonyl moiety were prepared via peptide coupling. The orthogonally protected glycoconjugates, bearing an acetyl-protected glycoside, were converted into their corresponding acids which are suitable building blocks for combinatorial glycopeptide synthesis.
\end{abstract}

\section{Introduction}

Glycans or other complex oligosaccharide structures, present on the surface of every prokaryotic and eukaryotic cell, are important for a large number of biological recognition processes like, for example, intercellular communication, signal transduction, pathogen recognition or immunological responses [1-4]. In order to investigate these processes it is essential that a large amount of the respective polysaccharide structure is available. Unfortunately, isolation of pure oligosaccharides from natural sources is difficult due to the micro heterogenity of naturally occurring saccharides. For this reason chemical oligosaccharide synthesis is the only alternative for providing sufficient amounts of pure material for detailed biological studies. However, the synthetic preparation of complex oligosaccharides is still difficult despite the great achievements in this field during the past decades. Therefore, the application of oligosaccharide mimetics which may be synthesized more easily in larger amounts appears to be a useful tool to investigate, for instance, specific carbohydrate-protein or carbohydrate-carbohydrate interactions. Recently our group has prepared a series of trifunctional glycopeptide building blocks with aliphatic backbones, which allow for the automated construction of combinatorial libraries of highly divers glycopeptides suitable for studying carbohydrate-protein interactions [5-8]. Hitherto, our focus was on glycosylated amino acid building blocks derived from aspartic acid and from the PNA-like $N$-(2-aminoethyl)glycine (AEG) backbone to which the sugar moieties were attached through either simple alkyl chains [5,6], amino alcohols [7,8] or 1,2,3triazoles [9-11]. These building blocks were used for combinatorial solid phase or automated spot synthesis of libraries of highly glycosylated peptides and shown to specifically bind to lectins $[5,8,10]$. Here, we now describe the preparation of a series of glycopeptide building blocks which allow for the 
construction of glycopeptide libraries with an aromatic backbone based on 3-aminomethyl-5-aminobenzoic acid to which the sugar moieties are attached through a malonyl linker. For that purpose we designed the two building blocks $\mathbf{1}$ and $\mathbf{2}$ (Figure 1) which both can be converted into the respective glycopeptides using standard Fmoc strategies [10].
1

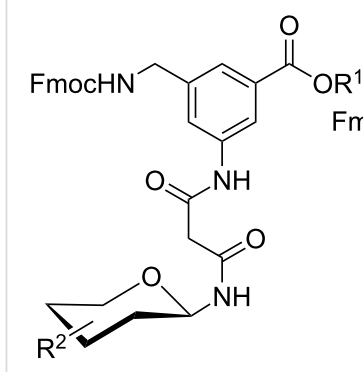

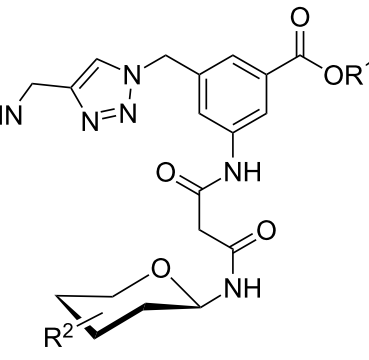

2
$\mathrm{R}^{1}=t-\mathrm{Bu}, \mathrm{H}$

$\mathrm{R}^{2}=\mathrm{OAc} / \mathrm{NHAc}$

Figure 1: Malonyl-linked aromatic glycoconjugate building blocks for spot synthesis of combinatorial glycopeptides libraries.

\section{Results and Discussion}

Our synthesis of building blocks $\mathbf{1}$ and $\mathbf{2}$ started from known 3-azidomethyl-5-nitrobenzoic acid methyl ester $\mathbf{3}$ which was prepared from commercially available dimethyl 5-nitroisophthalate in $64 \%$ overall yield $[12,13]$. Saponification of the methyl ester in $\mathbf{3}$ with aqueous $\mathrm{LiOH}$ solution in THF afforded the corresponding carboxylic acid 4 in $96 \%$ yield. Next, acid 4 was converted into tert-butyl ester $\mathbf{5}$ in $89 \%$ overall yield by a two-step procedure via the corresponding intermediate acid chloride (Scheme 1). Selective reduction of the azido group in $\mathbf{5}$ without affecting the nitro group was achieved with a Staudinger reaction [14]. Thus, treatment of 5 with triphenylphosphine in aqueous THF gave tert-butyl 3-aminomethyl-5nitrobenzoate which was not isolated but immediately converted into the corresponding Fmoc-protected derivative 6 in $78 \%$ overall yield. Final hydrogenation of the latter with Lindlar catalyst afforded 7 almost quantitatively. Likewise, copper(I)-catalyzed 1,3-dipolar cycloaddition (Click reaction) [15-18] of 5 with Fmoc-protected propargylamine afforded first $t$-butyl benzoate 8 in $87 \%$ yield. Hydrogenation of the latter with Pd on charcoal then gave 9 in $88 \%$ yield. It should be noted that hydrogenation of $\mathbf{6}$ and $\mathbf{8}$ had to be carefully optimized with respect to the reaction conditions in order to completely suppress the hydrogenation of the Fmoc group (Scheme 1).

For the construction of the two desired glycopetide building blocks 1 and $\mathbf{2}$ we needed a series of 1-malonylamidoglycopyranoses $\mathbf{1 2}$ for condensation with the aromatic backbone building blocks 7 and $\mathbf{9}$. For that purpose we chose four sugar ligands in the gluco, galacto, $\mathrm{N}$-acetylglucosamine and galactosamine series which were prepared as outlined in Table 1. Glycosylamines 10a-d were prepared from the corresponding glycosylazides by hydrogenation according to known pro-

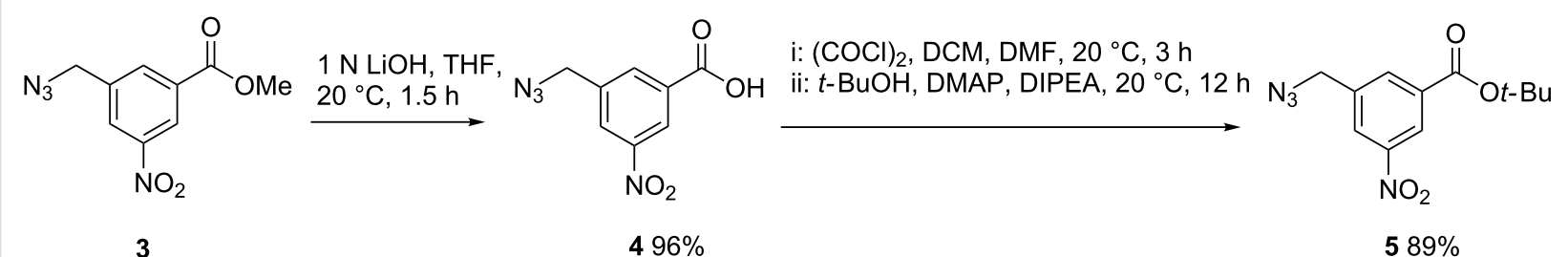

i: $\mathrm{PPh}_{3}, \mathrm{THF}, \mathrm{H}_{2} \mathrm{O}, 0-20^{\circ} \mathrm{C}, 20 \mathrm{~h}$ ii: FmocCl, DIPEA, DCM, $20^{\circ} \mathrm{C}, 22 \mathrm{~h}$

5<smiles>[B]OC(=O)c1cc(CNC(F)F)cc([N+](=O)[O-])c1</smiles>

$678 \%$

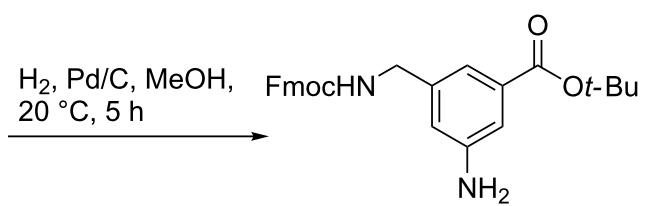

$799 \%$

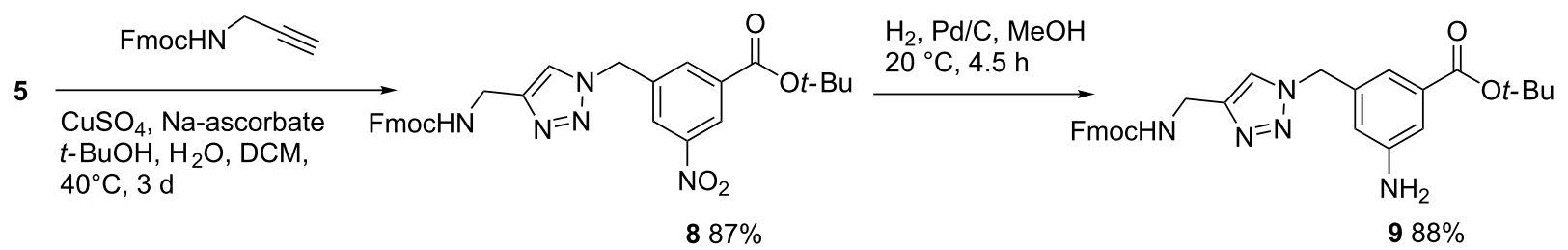


cedures [19-23]. Next, glycosylamines 10 were condensed with tert-butyl malonate [24], $N, N, N^{\prime}, N^{\prime}$-tetramethyl-O-(1H-benzotriazol-1-yl)uronium hexafluorophosphate (HBTU) and triethylamine in THF to give monosaccharides 11 in 53-76\% yield. The medium yields in case of $\mathbf{1 1} \mathbf{b}-\mathbf{d}$ (Table 1, entries 2-4) were due to some decomposition during chromatographic purification. Nevertheless, in our hands, HBTU was superior to other peptide coupling reagents because it resulted in the highest yields of compounds 11. HBTU was also previously used for the preparation of a similar $t$-butyl succinate of glucosamine [25]. Upon treatment with trifluoroacetic acid in dichloromethane, esters 11 were converted into the corresponding free acids 12 in $91-98 \%$ yield (Table 1 ).
Finally, glycopeptide building blocks $\mathbf{1}$ and $\mathbf{2}$ were prepared as follows (Table 2). Both Fmoc-protected benzoic acid derivatives 7 and 9 (Scheme 1) were each condensed with each of the four malonylamidoglycosides $\mathbf{1 2 a - d}$ (Table 1) to afford eight intermediate tert-butyl esters $\mathbf{1 3}$ and $\mathbf{1 4}$ in 45-67\% yield. For the condensation step between $\mathbf{7}$ and $\mathbf{9}$ with 12, respectively, we chose 1-ethyl-3-(3-dimethylaminopropyl)carbodiimide (EDCI) instead of HBTU as the coupling reagent because the side product (1-(3-(dimethylamino)propyl)-3-ethylurea) released from EDCI was easily removed from the crude reaction mixture by washing with aqueous citric acid. The medium yields for these condensation steps were due to some difficulties to completely separate the products from concomitant minor unidentified

Table 1: Synthesis of glycosides 11 and 12.

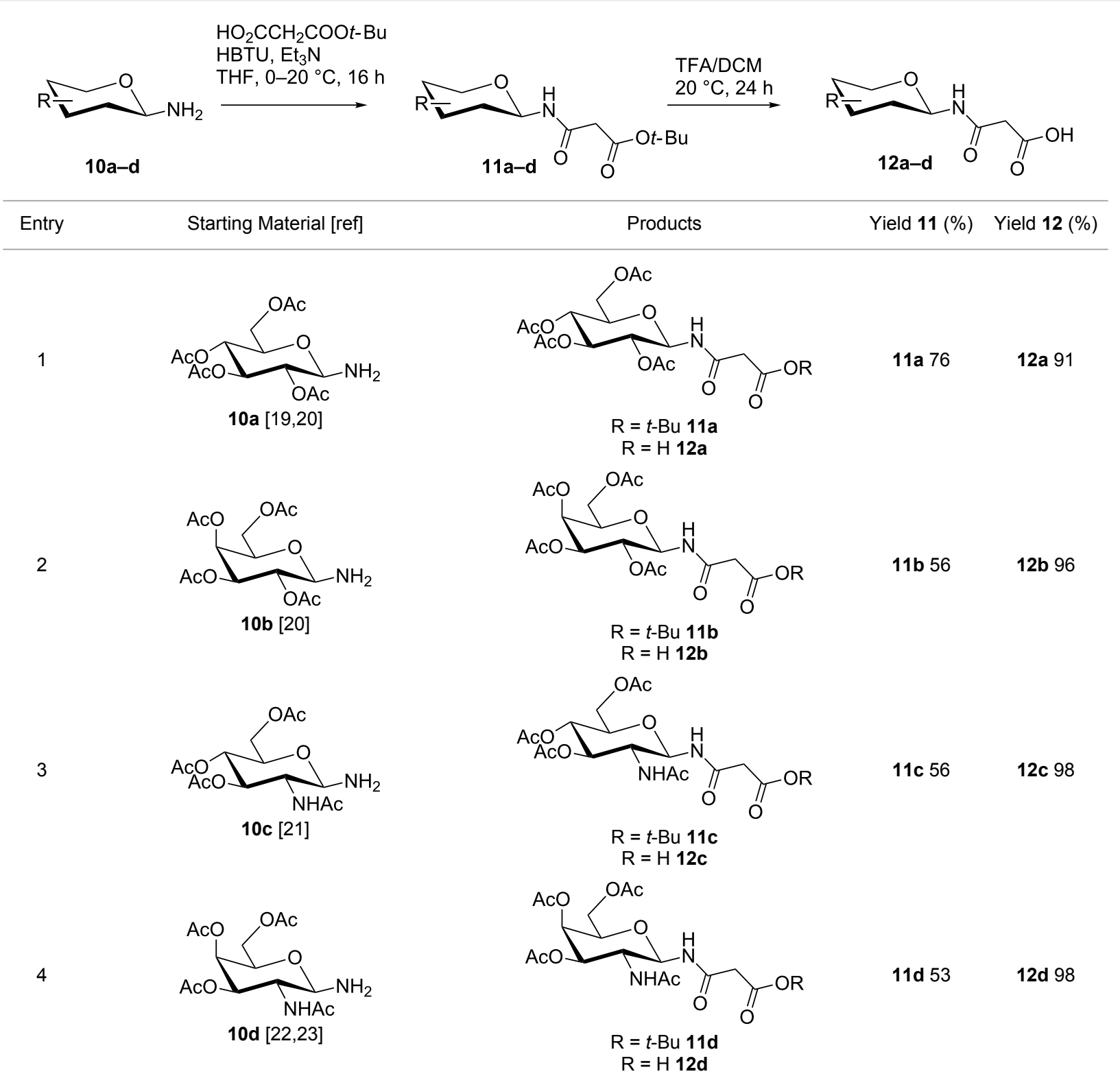


Table 2: Synthesis of glycopeptide building blocks 1 and 2.

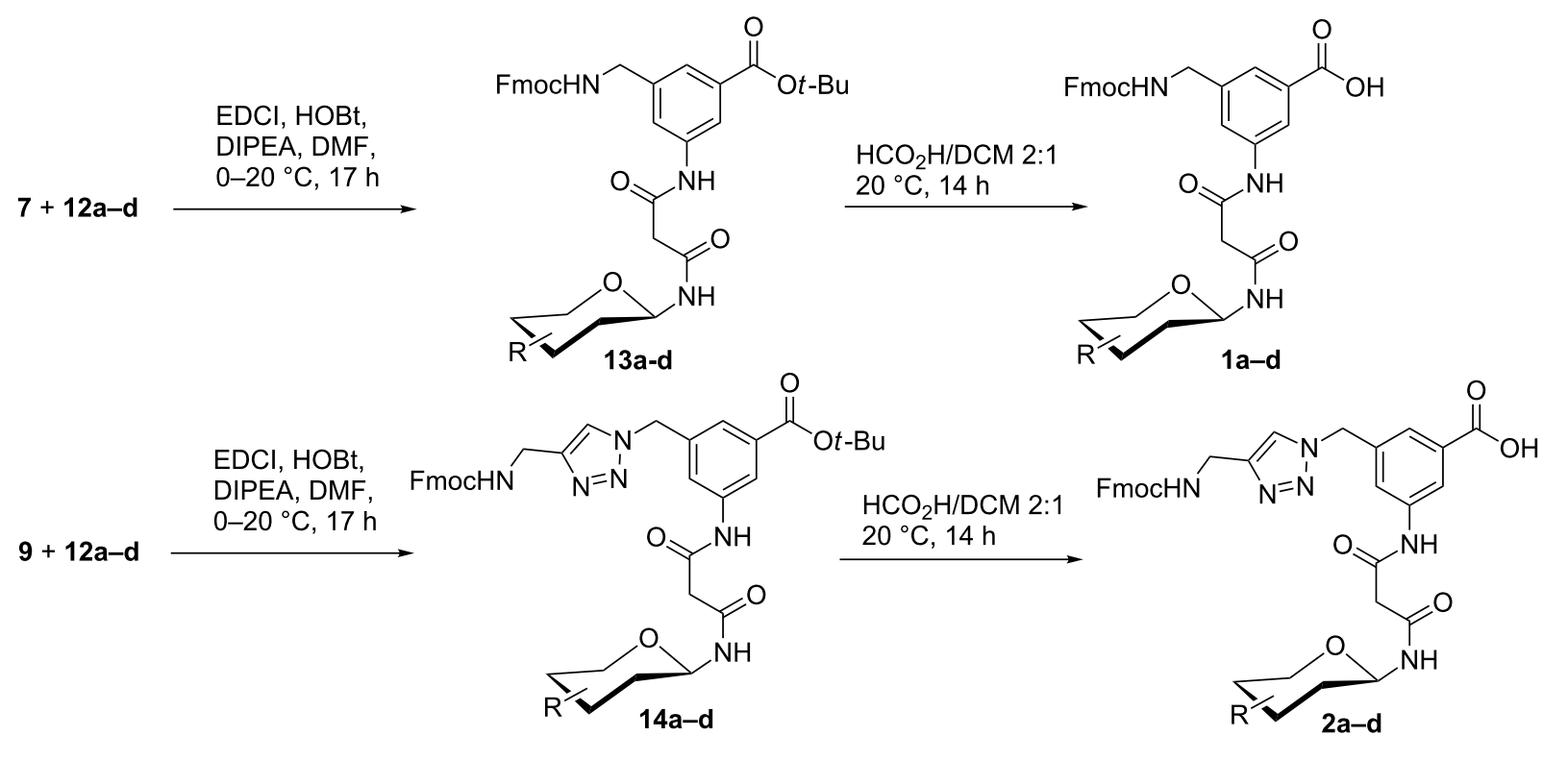

\begin{tabular}{lll}
\hline Entry & Products 13, 14 & Yield (\%) \\
\hline
\end{tabular}<smiles>CNC(=O)CC(=O)NC(OC(C)=O)[C@H]1OC(=O)O[C@H]1COC(C)=O</smiles>

$13 a$

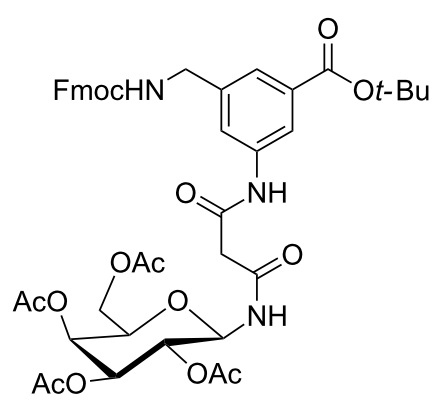

$13 b$

3

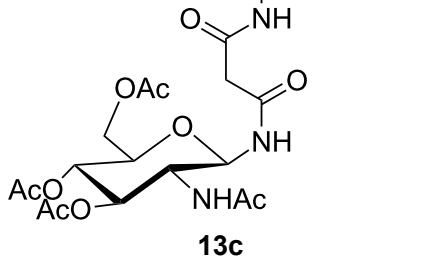

54<smiles>CC(=O)OCC(OC(=O)OCC(=O)NCc1cc(CNC(=O)O)cc(C(=O)O)c1)C(=O)O</smiles>

95

57

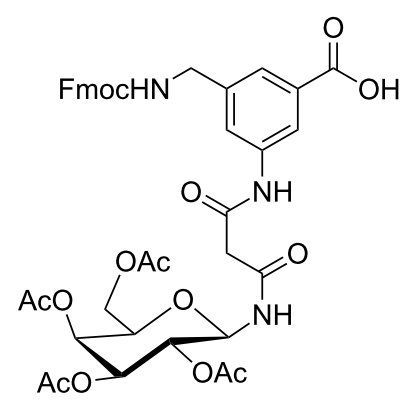

$1 b$

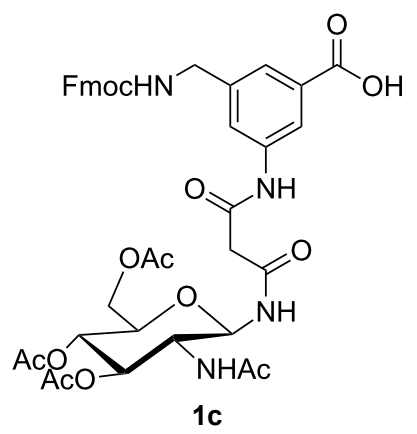

90 
Table 2: Synthesis of glycopeptide building blocks 1 and 2. (continued)

4<smiles>CCCCOC(=O)c1cc(CNC(F)F)cc(NNC(F)F)c1</smiles>

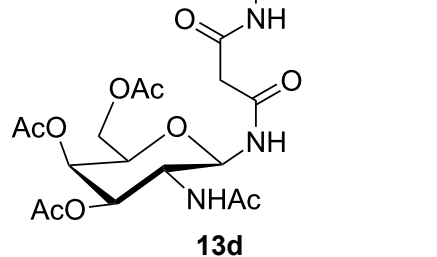<smiles>CCC(C)OC(=O)c1cc(N)cc(Cn2cc(CNC(F)F)nn2)c1</smiles>

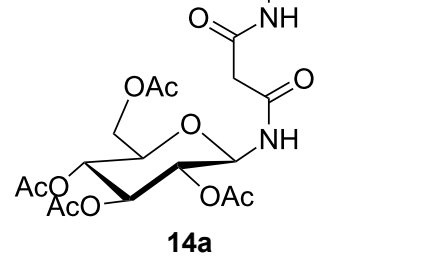<smiles>CCC(C)OC(=O)c1cc(N)cc(Cn2cc(CNC(F)F)nn2)c1</smiles>

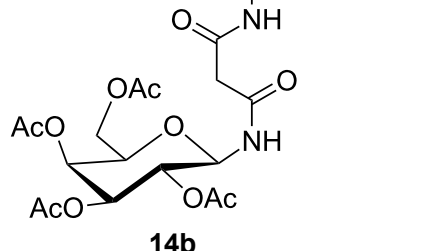

14b<smiles>CCCCOC(=O)c1cc(N)cc(Cn2cc(CNC(F)F)nn2)c1</smiles>

7

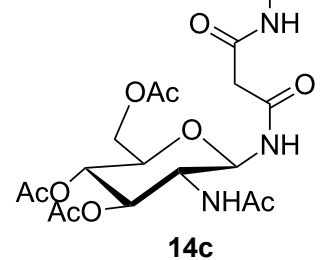<smiles>CCCCNCc1cn(Cc2cc([N])cc(C(=O)OCC(F)F)c2)nn1</smiles>

8

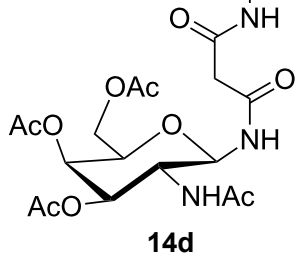

61

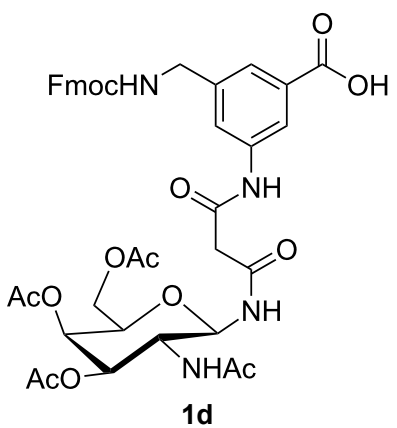

94

92

84

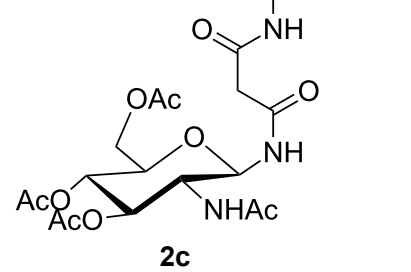<smiles>Nc1cc(Cn2cc(CNC(F)F)nn2)cc(C(=O)O)c1</smiles>

94 
byproducts which showed similar mobilities during chromatographic purification. Next, the tert-butyl ester groups of compounds $\mathbf{1 3}$ and $\mathbf{1 4}$ were hydrolysed with a 2:1 mixture of formic acid and dichloromethane at room temperature to give the corresponding free acids, i.e., building blocks $1 \mathbf{a}-\mathbf{d}$ and $\mathbf{2 a - d}$ in $68-95 \%$ yield (Table 2 ).

In order to demonstrate that building blocks $\mathbf{1}$ and $\mathbf{2}$ are indeed suitable for the construction of combinatorial glycopeptide libraries we chose glucose-containing derivatives 1a and 2a for an exemplified preparation of the corresponding fully protected dimers. For comparison reasons and the possibility to later construct glycopeptides containing non-glycosylated chain links, we also prepared two dipeptides from nitro-benzoates $\mathbf{6}$ and $\mathbf{8}$ in the following way (Scheme 2). Treatment of $\mathbf{6}$ and $\mathbf{8}$ with a 2:1 mixture of formic acid and dichloromethane at room temperature for $38 \mathrm{~h}$, as described for the preparation of building blocks $\mathbf{1}$ and $\mathbf{2}$ (see Table 2), afforded the benzoic acid

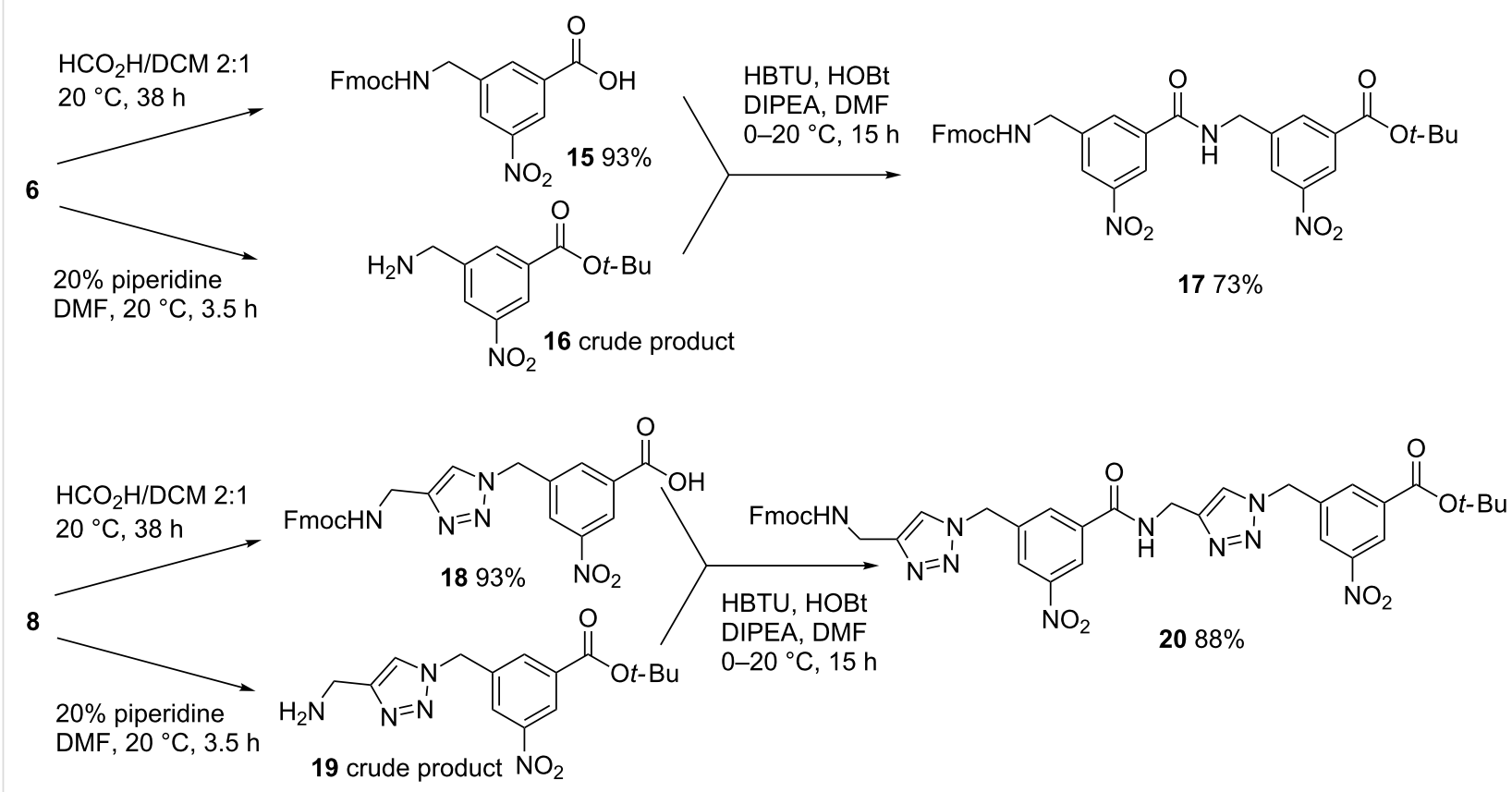

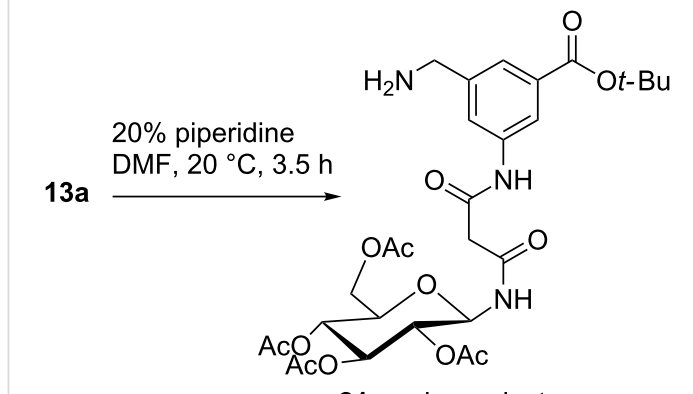

21 crude product
$1 \mathrm{a}$

HBTU, HOBt DIPEA, DMF $0-20^{\circ} \mathrm{C}, 15 \mathrm{~h}$

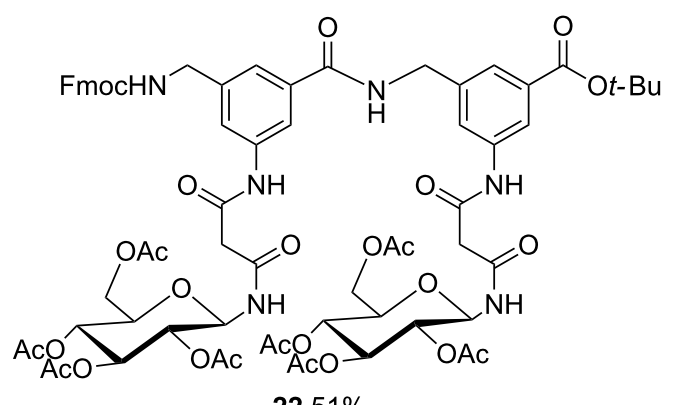

$2251 \%$

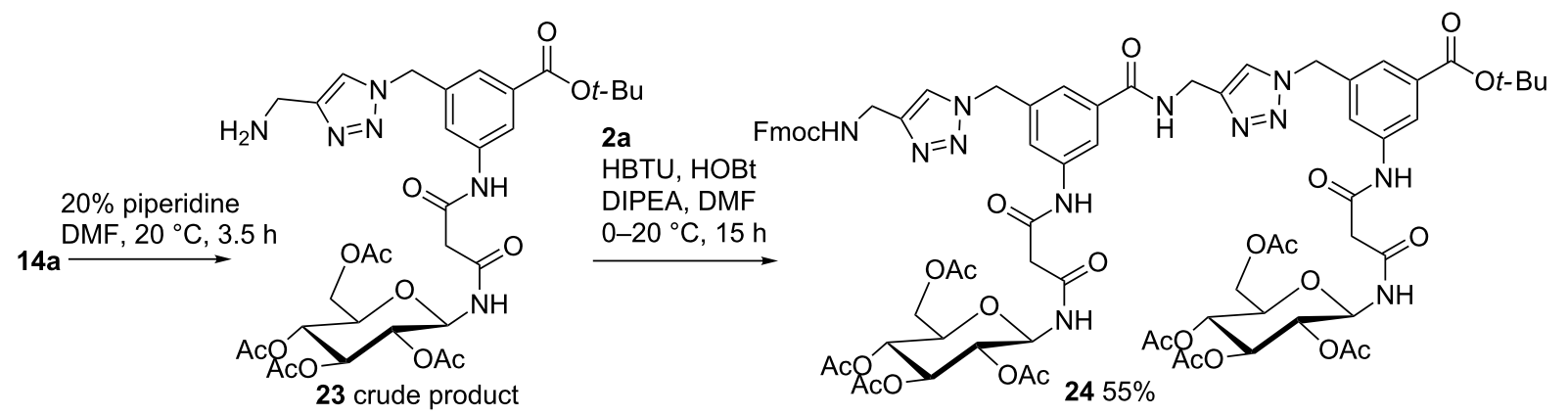


derivatives $\mathbf{1 5}$ and $\mathbf{1 8}$ in 93\% yield for each. Likewise, treatment of $\mathbf{5}$ and $\mathbf{8}$ with $20 \%$ piperidine in DMF at room temperature for 3.5 h gave crude aminomethyl compounds $\mathbf{1 6}$ and 19 which were used for the next step without further purification. Final coupling of 15 with 16 and 18 with 19 using HBTU, 1-hydroxybenzotriazole (HOBt) and diisopropylethylamine (DIPEA) in DMF as the condenation agent gave non-glycosylated fully protected dipeptides $\mathbf{1 7}$ and $\mathbf{2 0}$ in $73 \%$ and $88 \%$ yield, respectively (Scheme 2). Likewise, the Fmoc protecting groups in glucosylated building blocks 13a and 14a were first removed with piperidine in DMF to give crude aminomethyl derivates $\mathbf{2 1}$ and 23. Next, the latter were coupled with $\mathbf{1 a}$ (for 21) and 2a (for 23) under similar conditions as described for the non-glycosylated counterparts above to afford glycol-dipeptides 22 and $\mathbf{2 4}$ in 51\% and 55\% yield, respectively. As was observed for EDCI-promoted preparation of glycosylated derivatives 13 and 14 (see Table 2), the yields of the two glucodipeptides were only in the medium range due to traces of unidentified byproducts which could not easily removed during chromatographic purification. Nevertheless, the only medium yields in this case can be circumvented in solid phase syntheses of such glycopeptides where an excess of one building block can be applied and no chromatographic purification is necessary. Such combinatorial solid phase syntheses with the building blocks described here are now underway.

\section{Conclusion}

We have described the preparation of a series of new aromatic glycopeptoids and have demonstrated their usefulness for the preparation of corresponding glycosylated or non-glycosylated dipeptides. The benzoic acid derived building blocks described here will be used in combination with previously described similar glycopeptoids based on asparaginic acid or PNA-like backbones for automated SPOT syntheses of combinatorial glycopeptide libraries which will be screened for their capability to bind to specific proteins [5-11]. Those results will be published elsewhere.

\section{Supporting Information}

\section{Supporting Information File 1 \\ Experimental data. \\ [http://www.beilstein-journals.org/bjoc/content/ supplementary/1860-5397-10-256-S1.pdf]}

\section{Supporting Information File 2}

NMR Spectra.

[http://www.beilstein-journals.org/bjoc/content/ supplementary/1860-5397-10-256-S2.pdf]

\section{Acknowledgements}

We thank Dr. Dorothee Wistuba for the measurement of the high resolution mass spectra, Dr. Markus Kramer and the members of the NMR-division of the Institute of Organic Chemistry for recording the NMR spectra and Petra Krüger for performing the elemental analyses. We also thank Dr. Gregor Lemanski for numerous discussions on the topic.

\section{References}

1. Benett, H. S. J. Histochem. Cytochem. 1963, 11, 14-23. doi:10.1177/11.1.14

2. Lee, Y. C.; Lee, R. T. Acc. Chem. Res. 1995, 28, 321-327. doi:10.1021/ar00056a001

3. Dwek, R. A. Chem. Rev. 1996, 96, 683-720. doi:10.1021/cr940283b

4. Solis, D.; Romero, A.; Menendez, M.; Jimenez-Barbero, J. In The Sugar Code; Gabius, H.-J., Ed.; Wiley-Blackwell: Weinheim, 2009; p 233.

5. Ziegler, T.; Röseling, D.; Subramanian, L. R. Tetrahedron: Asymmetry 2002, 13, 911-914. doi:10.1016/S0957-4166(02)00212-4

6. Daiber, R.; Ziegler, T. ARKIVOC 2013, No. ii, 408-420.

7. Schips, C.; Ziegler, T. J. Carbohydr. Chem. 2005, 24, 773-788. doi:10.1080/07328300500326859

8. Ziegler, T.; Schips, C. Nat. Protoc. 2006, 1, 1987-1994. doi:10.1038/nprot.2006.307

9. Pietrzik, N.; Schips, C.; Ziegler, T. Synthesis 2008, 519-526. doi:10.1055/s-2008-1032150

10. Günther, K.; Schips, C.; Ziegler, T. J. Carbohydr. Chem. 2008, 27, 446-463. doi:10.1080/07328300802419873

11. Günther, K. U.; Ziegler, T. Synthesis 2014, 46, 2362-2370. doi:10.1055/s-0033-1339137

12. Harris, T. D.; Rajopadhye, M.; Damphousse, P. J.; Glowacka, D.; Yu, K.; Bourque, J. P.; Barrett, J. A.; Damphousse, D. J.; Heminway, S. J.; Lazewatsky, J.; Mazaika, T.; Carroll, T. R. Bioorg. Med. Chem. Lett. 1996, 6, 1741-1746. doi:10.1016/0960-894X(96)00282-X

13. Watzke, A.; Gutierrez-Rodriguez, M.; Köhn, M.; Wacker, R.; Schroeder, H.; Breinbauer, R.; Kuhlmann, J.; Alexandrov, K.; Niemeyer, C. M.; Goody, R. S.; Waldmann, H. Bioorg. Med. Chem. 2006, 14, 6288-6306. doi:10.1016/j.bmc.2006.05.006

14. Staudinger, H.; Meyer, J. Helv. Chim. Acta 1919, 2, 635-646. doi:10.1002/hlca.19190020164

15. Rostovtsev, V. V.; Green, L.; Fokin, V. V.; Sharpless, K. B. Angew. Chem., Int. Ed. 2002, 41, 2596-2599. doi:10.1002/1521-3773(20020715)41:14<2596::AID-ANIE2596>3.0.CO ;2-4

16. Tornoe, C. W.; Christensen, C.; Meldal, M. J. Org. Chem. 2002, 67, 3057-3064. doi:10.1021/jo011148j

17. Bock, V. D.; Hiemstra, H.; van Maarseveen, J. H. Eur. J. Org. Chem. 2006, 51-68. doi:10.1002/ejoc.200500483

18. Dedola, S.; Nepogodiev, S. A.; Field, R. A. Org. Biomol. Chem. 2007, 5, 1006-1017. doi:10.1039/b618048p

19. Helferich, B.; Mitrowsky, A. Chem. Ber. 1952, 85, 1-8. doi:10.1002/cber.19520850103

20. Badia, C.; Souard, F.; Vicent, C. J. Org. Chem. 2012, 77, 10870-10881. doi:10.1021/jo302238u

21. Neumann, J.; Thiem, J. Eur. J. Org. Chem. 2010, 900-908. doi:10.1002/ejoc.200901106 
22. Dunstan, D.; Hough, L. Carbohydr. Res. 1972, 25, 246-248. doi:10.1016/S0008-6215(00)82766-4

23. Tanaka, M.; Yamashina, I. Carbohydr. Res. 1973, 27, 175-183. doi:10.1016/S0008-6215(00)82437-4

24. Tararov, V. I.; Korosteylev, A.; König, G.; Börner, A. Synth. Commun. 2006, 36, 187-191. doi:10.1080/00397910500334405

25. Fujita, Y.; Abdel-Aal, A.-B. M.; Wimmer, N.; Batzloff, M. R.; Good, M. F.; Toth, I. Bioorg. Med. Chem. 2008, 16, 8907-8913. doi:10.1016/j.bmc.2008.08.064

\section{License and Terms}

This is an Open Access article under the terms of the Creative Commons Attribution License

(http://creativecommons.org/licenses/by/2.0), which permits unrestricted use, distribution, and reproduction in any medium, provided the original work is properly cited.

The license is subject to the Beilstein Journal of Organic Chemistry terms and conditions:

(http://www.beilstein-journals.org/bjoc)

The definitive version of this article is the electronic one which can be found at: $\underline{\text { doi: } 10.3762 / \text { bjoc. } 10.256}$ 